\title{
MODELING OF THE DETECTION SYSTEM OF FLYING OBJECTS
}

\author{
A. Pincevičius, A. Vyšniauskas, P. Jankauskas
}

The General Jonas Žemaitis Military Academy of Lithuania. E-mail: pincev@takas.lt Received 2004 2004, accepted 26072004

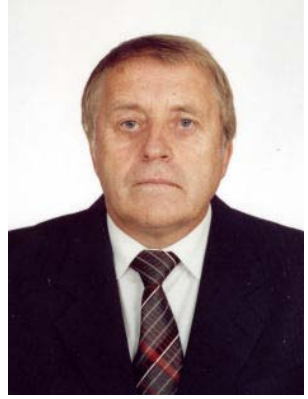

Albertas PINCEVIČIUS, Assoc Prof Dr

Date and place of birth: 1944 in Šeduva, Lithuania.

Education: 1970 - Faculty of Physics of Vilnius University.

Affiliations and functions: 1980 - Doctor.

Research interests: Mathematical Modelling Operation: Modelling of Examinations of Semiconductor Materials, Semiconductor Frames, Problems of Optimisation of Military Operations.

Teaching: Mathematics.

Publications: Author of more than 30 scientific articles; co-author of manual and two textbooks.

Present Position: Associate Professor inf Department of Applied Sciences at General Jonas Žemaitis Military Academy of Lithuania.

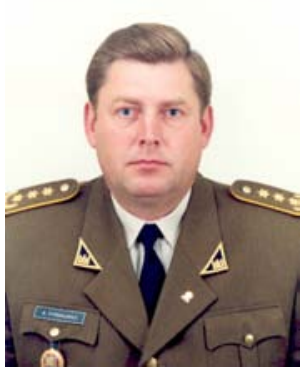

\section{Algimantas VYŠNIAUSKAS, Col}

Date and place of birth: Varéna district, in 1954.

Education: Vilnius Higher Military Radio Electronics Air Defence Commander School in 1972-1976, Tverj Air Defence Commander Military Academy in 1989-1992.

Positions: Company commander in 1978-1985, Chief of staff and battalion commander of radio-technical battalion in 1985-1989, Commander of the Cadet Corps, National Defence School in 1992-1994, Deputy Rector of Military Academy of Lithuania in 1994-1998, Director of the airspace control project in 1999-2000, Deputy commander, Training and Doctrine Command of the Lithuanian Armed Forces in 2000-2003, from 2003 Acting Chief of General Jonas Žemaitis Academy of Lithuania.

Awards: Third Degree Order of the Lithuanian Grand Duke Gediminas, Armed Forces medal for merits.

Field of research: Airspace control and defence systems.

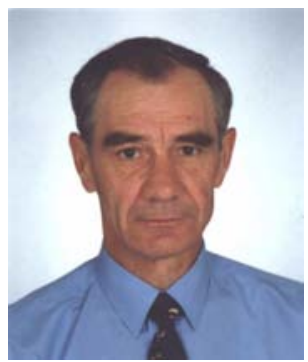

Pranas JANKAUSKAS, Dr

Date and place of birth: 1945 in Ančènai, Molètai District, Lithuania

Education: 1976 - Engineering Academy of Moscow; 1981 - Adjuncture of Engineering Academy of Moscow, Affiliations and functions: 1982 - Scientific Degree of Doctor.

Publications: Author of more than 70 scientific articles.

Inventions: 37 inventions.

Awards: 1994 - Third Degree Order of Gediminas.

Present position: Deputy Chief of General Jonas Žemaitis Academy of Lithuania.

\begin{abstract}
A scheme for the dislocation of 3D radar is proposed, and the process of the detection of a flying object is discussed in this paper. The formulae for the evaluation of the probability of detection of a flaying object in case of surveillance by one radar or radar system proposed. The cases are discussed when the probabilistic density of the detection of a flying object is expressed by Normal Distribution or Relay Distribution (in case of bad meteorological conditions). A quantitative estimation of a detection system with concrete parameters is done. The results of the calculation allow the efficiency of the surveillance system to be estimated. The method of calculations can be used for study or for the estimation of the systems of detection of a flying object.
\end{abstract}

Keywords: Poisson Process, probability of detection, radar system.

\section{Introduction}

This paper proceeds with the modeling of the detection system of flying objects. The method of the dislocation of radar installations is established, their parameters are chosen, and the detection process of flying objects is discussed. The probability of the detection of a flying object at some fixed distance by one radio location station and by its system is calculated and diagrams of probabilistic fields are drawn. Taking the technical characteristics of various types of radars and meteorological conditions into account carries out the quantitative estimation of such a system.

\section{Statement of the problem}

In order to ensure the reliability of the surveillance of some airspace zone, we suggest situating the 3D radar stations following the scheme indicated in Fig 1. 


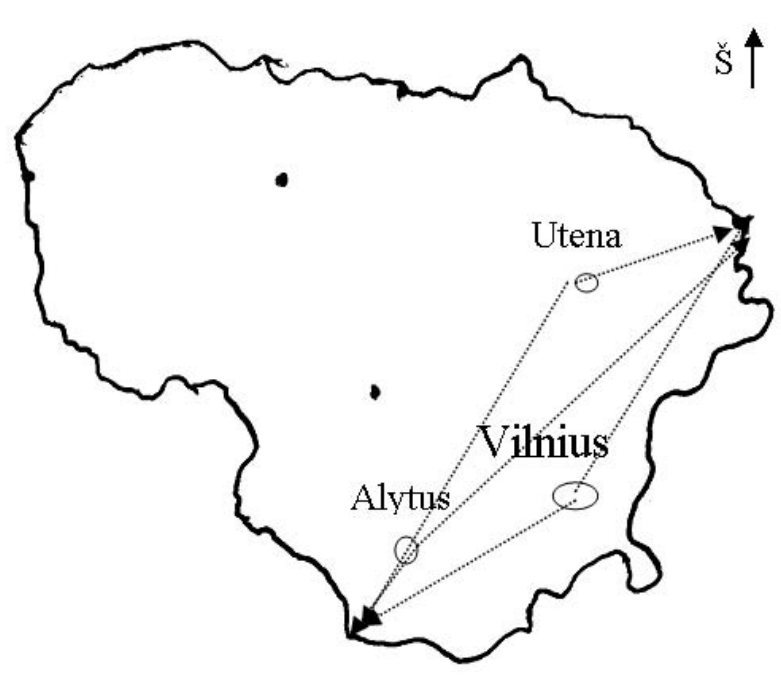

Fig 1. Hypothetical scheme. Arrows indicate the sector of visibility

We will investigate the most unfavorable case for the detection system - the case when we have the least time for the detection of a flying object. Such a situation is represented in Fig 2. In this case we must choose the parameters of the radar station in such a manner that the object be detected with the desirable probability within a definite distance. The possibility of the detection of the object depends not only on the properties of the radar, but also on the meteorological conditions, the parameters of the object, reflective properties and possible hindrances.

\section{The process of the detecting of flying object}

In practice radar activity is characterized by the momentary probability of the detection of a flying object (the probability of detection during one observation) [4]:

$$
g=\frac{1}{\bar{n}(r)}
$$

where $\bar{n}(r)$ is the mean number of observations necessary for detecting an object within a certain distance $\mathrm{r}$ (under certain meteorological conditions and with standard properties of flying objects). This quantity may be determined by experiment in each specific case.

The Queuing Theory will be utilized for the theoretical evaluation of this probability. During the process of the detection of a flying object, all the conditions of Poisson Process are satisfied: stationarity, ordinariness, and independence of events. In this case the probability of the "capture" of at least one object may be written:

$$
P(t)=1-e^{-\lambda t},
$$

here $\lambda$ - intensity of flow (the number of demands during the unit of time).

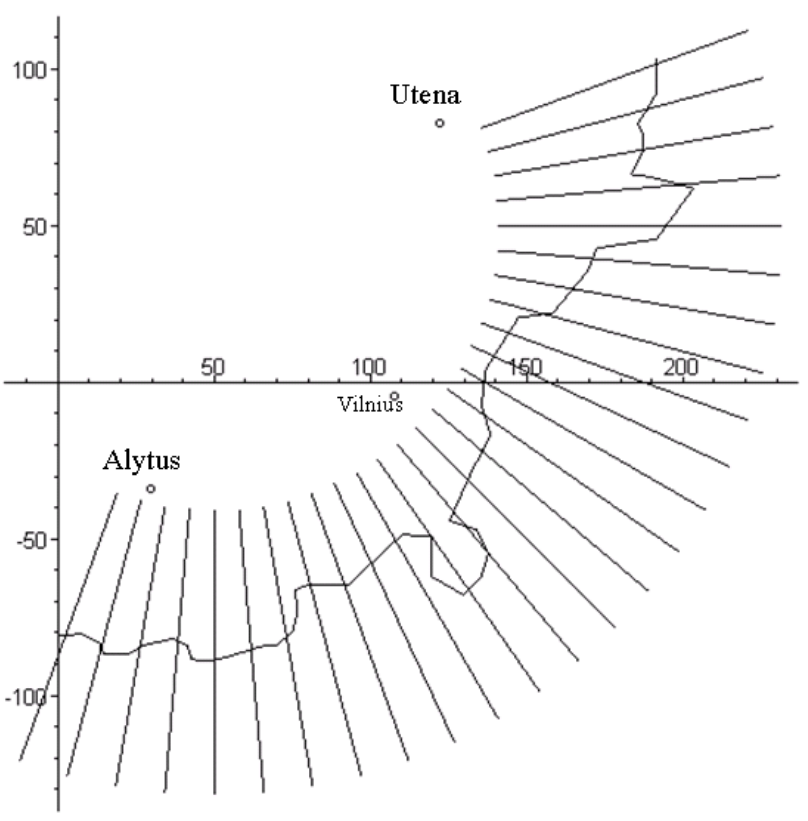

Fig 2. Chosen paths of a moving object

One of the most important factors determining the probability of detection is the distance to the flying object. The probability $P(r)$ that is the probability of the "capture" of a flying object in the distance $r$ may be presented by the formula [3]:

$$
P(r)=1-e^{-\varphi(r)}
$$

where $\lambda$ is the intensity of flow (the number of demands during the unit of time).

One of the most important factors determining the probability of detection is the distance to the flying object. The probability $P(r)$ - the probability of the "capture" of a flying object in the distance $r$ - may be presented by the formula [3]:

$$
P(r)=1-e^{-\varphi(r)},
$$

where $\varphi(r)$ is the so-called "potential of detection". The variable $g$ is connected with the derivative of the potential of detection $f(r)=\frac{d \varphi(r)}{d r}$ that describes the intensity of the detection of objects [3]:

$$
g=1-e^{-f(r) v \Delta T},
$$

We denominate $v$ is as the velocity of the flying object, $\Delta T$ - period of observation, because flying objects are most frequently observed by the instrument working in an impulse regime and within periods of certain duration.

\section{Estimation of probability of the detection of a flying object}

In many cases the probability of the detection of a flying object may be expressed by Normal Distribution: 


$$
\begin{aligned}
& P(r)=\frac{1}{\sqrt{2 \pi} \sigma_{r}} \int_{0}^{r} e^{-\frac{\left(r-r_{a}\right)^{2}}{2 \sigma_{r}^{2}}} d r=\int_{0}^{r} p(r) d r \\
& p(r)=\frac{1}{\sqrt{2 \pi} \sigma_{r}} e^{-\frac{\left(r-r_{a}\right)^{2}}{2 \sigma_{r}^{2}}},
\end{aligned}
$$

where $p(r)$ is the probabilistic density of the detection of a flying object, $r_{a}$ is the mean distance within which a flying object is detected, and $\sigma_{r}$ is the mean square deviation (the error of $r_{a}$ ).

We get from (3) and (5):

$$
\begin{aligned}
& \varphi(r)=-\ln (1-P(r)) \text { and } \\
& f(r)=\frac{P^{\prime}(r)}{1-P(r)}=\frac{p(r)}{1-P(r)} .
\end{aligned}
$$

In case the efficiency of the radar station is low, for example due to bad meteorological conditions, Relay Distribution can be applied. In this case the density of the probability of distributions is written:

$$
p(r)=\frac{r}{\sigma_{r}^{2}} e^{-\frac{r^{2}}{2 \sigma_{r}^{2}}}
$$

For the numerical evaluation of the radar surveillance system, it is necessary to know some principal parameters of the radar station and the flying object. For example [1, 2]:

mean distance of the detection of the object $r_{a}=150 \mathrm{~km}$,

the rate of the turn of the antenna - 6 times per minute,

the resolution along to the azimuth - $\Delta \alpha=3^{0}$,

the speed of the flying object $v=330 \mathrm{~m}$.

The mean square deviation may be estimated by the formula (see [3])

$$
\sigma_{r}=\frac{1}{6}\left(k_{1}^{\prime} k_{2}^{\prime} k_{3}^{\prime}-k_{1}^{\prime \prime} k_{2}^{\prime \prime} k_{3}^{\prime \prime}\right) r_{a} \text {, }
$$

where coefficients $k_{i}^{\prime}$ and $k_{i}^{\prime \prime}$ enable us to take meteorological conditions, properties of the radar, and character of the target into account. Coefficient $k_{i}^{\prime}$ corresponds to the best estimations (from 1 to 1.5 ) and $k_{i}^{\prime \prime}$ corresponds to the worst ones (from 0,5 to 1 ).

If we appreciate the activity of radar under normal conditions, we apply Normal Distribution and we take these mean values of coefficients:

$$
\begin{aligned}
& k_{1}^{\prime}=1,1-1,2, k_{2}^{\prime}=1,1-1,2, k_{3}^{\prime}=1,1-1,2 \text { and } \\
& k_{1}^{\prime \prime}=0,8-0,9, k_{2}^{\prime \prime}=0,8-0,9, k_{3}^{\prime \prime}=0,8-0,9 .
\end{aligned}
$$
interval

We obtain the mean quadratic deviation in Inc

$$
0,1 r_{a} \leq \sigma_{r} \leq 0,2 r_{a}
$$

Therefore, in case of Normal Distribution we shall take the value of the mean quadratic deviation $\sigma_{r}^{n}$ as being equal to

$$
\sigma_{r}^{n}=0,1 r_{a}
$$

In case of very bad meteorological conditions, it is necessary to apply the Relay Distribution and evaluate the activity of the radar station using boundary scale numbers:

$$
k_{1}^{\prime \prime}=0,5, k_{2}^{\prime \prime}=0,5, k_{3}^{\prime \prime}=0,5 \text {. }
$$

In this case the mean quadratic deviation will be

$$
\sigma_{r}^{R}=0,25 r_{a} \text {. }
$$

Keeping in mind that the radar antenna turns round in about 10 seconds, in every rotation each angle of observation, $\Delta \alpha=3^{0}$, can be "seen" for $1 / 12 \approx 0.083 \mathrm{sec}$ : the period of observation is $\Delta T \approx 0.083 \mathrm{sec}$. During this time, the observed object with a velocity of movement $\mathrm{v}=330 \mathrm{~m} / \mathrm{sec}$ flies no more than 28 meters. We can consider its distance from the radar during the period of observation equal to constant because that distance is not less than 50 kilometers and error is negligible. The flying object may be observed within the distance $\mathrm{r}$ about 50 - 200 kilometers from the radar station and can be "seen" $n=150 /(0,33 \times 10) \approx 46$ times (antenna rotating 10 $\mathrm{sec})$.

If the probability of the detection of a flying object in one observation is equal to $g$, then the probability for one radar to detect the object within the interval of observation $\Delta r \approx 150 \mathrm{~km}$, that is to detect at least once in $n$ experiments may be written so (every "capture" is an independent event and the probability of an opposite event is equal to $1-g_{i}$ ):

$$
P_{n}=1-\left(1-g_{1}^{1}\right)\left(1-g_{2}^{1}\right) \ldots\left(1-g_{n}^{1}\right) .
$$

In case several radar stations try to "capture" the flying object, the exact formula of detecting the object is equal to:

$$
g=g^{1}+g^{2}+. .
$$

where $g^{i}$ stands for the probability of detecting the object with one radar.

Now we will carry out the numerical evaluation of the investigated surveillance system.

\section{Results and discussion of computations}

We shall evaluate the probability of the detection of a flying object in case the airspace surveillance system 
consists of three uniform radar stations (Fig 1). The graphs of probabilistic density of the detection of a flying object are represented in Fig 3. In Fig 4 one can see the dependence of instantaneous detection probabilities on distance.

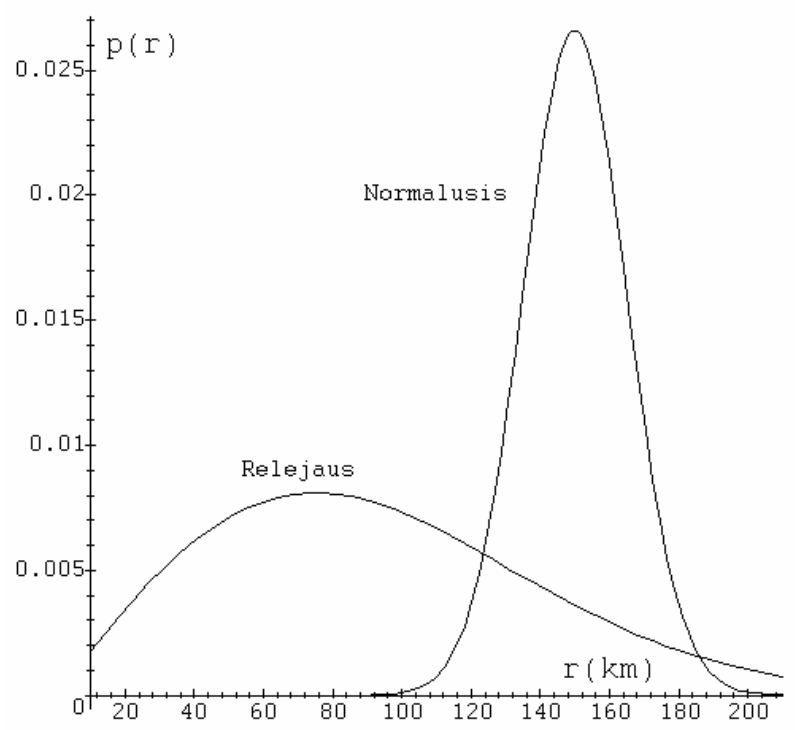

Fig 3. Dependence of the probability density of the detection of a flying object on its distance from the radar: Normal

Distribution $\sigma_{r}^{n}=0,1 r_{a}$, Relay Distribution

$$
\sigma_{r}^{R}=0,25 r_{a}
$$

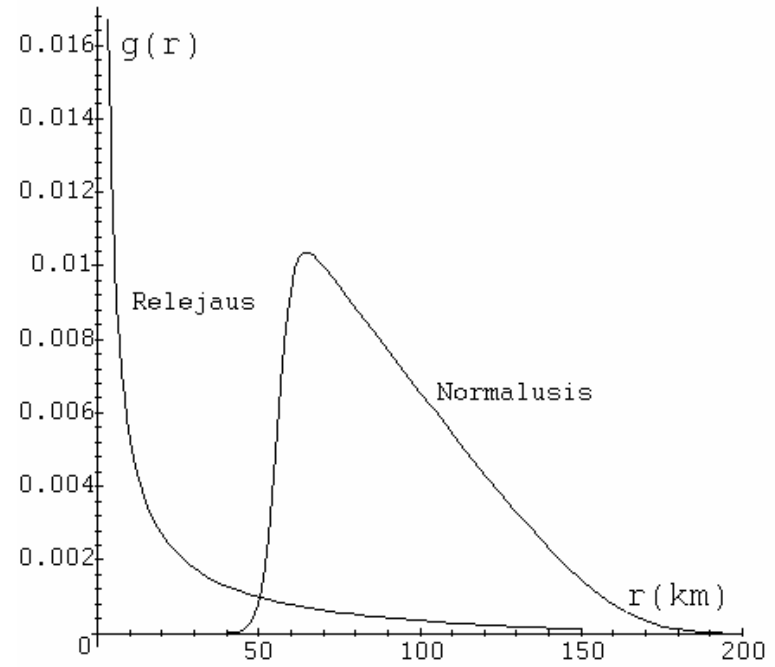

Fig 4. Probability of the detection of a flying object during one radar surveillance period $\Delta T$ equal to $g(r) . \quad 1-$ in case of Normal Distribution 2 - Relay Distribution

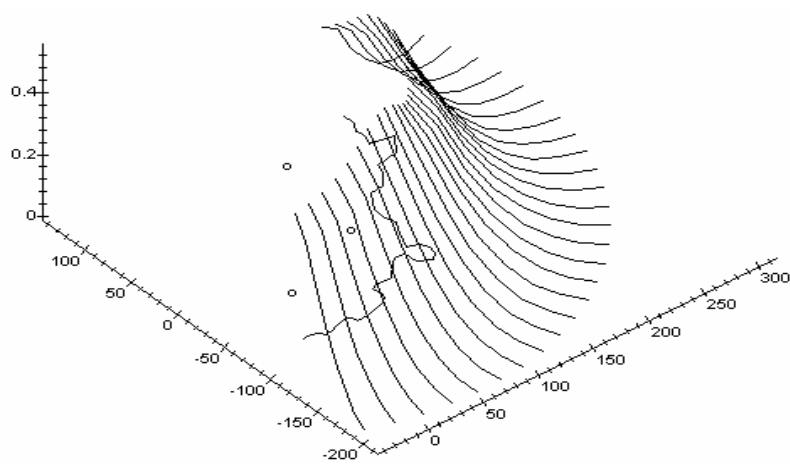

Fig 5. The probability of detecting a flying object. Normal Distribution

in this case: $r_{a}=150 \mathrm{~km}, \sigma_{r}=0.1 r_{a}=15 \mathrm{~km}$

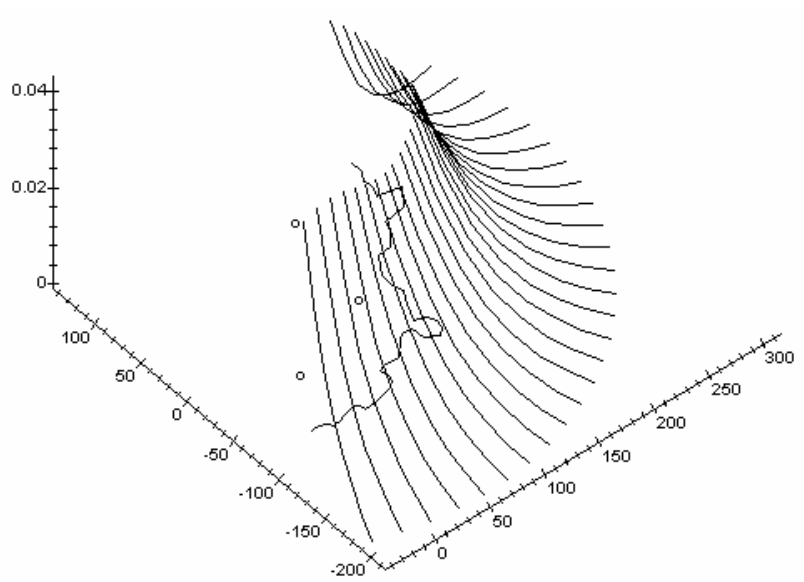

Fig 6. Probability of detecting a flying object by a system of radars. Relay distribution in this case: $r_{a}=150 \mathrm{~km}, \sigma_{r}=75 \mathrm{~km}$

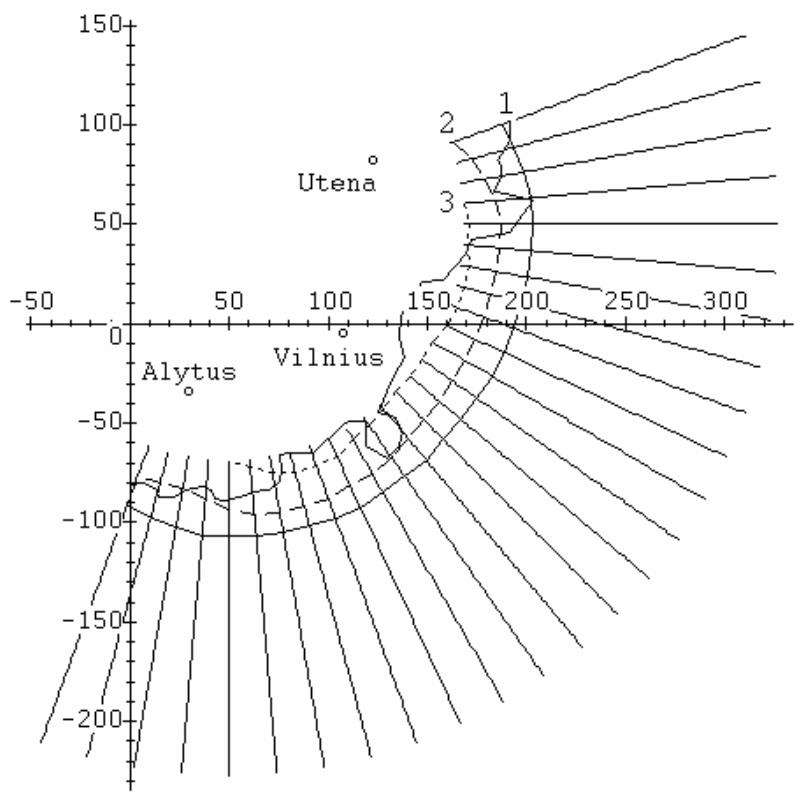

Fig 7. Probability of detecting a flying object by a system of radars (Normal Distribution).

Equipotential lines: 1 curve $-P=0,25, \quad 2-P=0,35$ and $3-P=0,45$ 
The graph visually shows that the probability of the detection of a flying object very strongly depends on meteorological conditions. Further, by using formulae (9) and (10), detection probabilities when the object moves along the trajectories indicated in Fig 2 and when all three radars are in action can be found. The results of these computations (probabilistic fields) are revealed in Fig 5 (Normal Distribution) and Fig 6 (Relay Distribution). We see that with Relay Distribution the probability of the detection of a flying object is less by one order compared to the case with Normal Distribution. For practical use we recommend the figures where the equipotential lines of the probabilities of detection are represented (Fig 7). We observe that in case of favorable air-conditions the probability of detection amounts to $45 \%$. The placement of equipotential lines is also usable, that is the placement of radar stations is usable. In order to achieve better parameters of the detection system more radar units are necessary, especially under poor meteorological conditions.

These programs may be used for the estimation of detection systems of flying objects, the selection of radar parameters, the number of radar stations, and the placement of radar. They are usable both for teaching and for designing of such systems.

\section{Conclusions}

The detection process of a flying object is discussed, and a scheme for the placement of 3D radars is proposed in this paper. Taking the technical characteristics of radar and meteorological conditions into account carries out the quantitative estimation of such a system. The probability of the detection of a flying object at some fixed distance by a radar system is calculated, and diagrams of probabilistic fields are drawn.

These programs may be used for the estimation of detection systems of flying objects and for the quantity, and placement selection of radar parameters. They can be used to design of such systems. Method of calculations can be used for study process.

\section{References}

1. Pincevičius A., Rakauskas R.J. Skraidančio objekto geografinès padèties nustatymo radiolokacijos priemonemis optimizavimas // Aviacija. - V.: Technika, 2002. - Nr.6. - P. 74 - 78.

2. Schlesinges R.J. Principles of Electronic Warfare / Prentice-Hall, INC., - New Jersey, 1961. - 315 p.

3. Горбунов В.А. Эффективность обнаружения целей. - Москва: Воениздат, 1979. - 160 с. 